\title{
Mini-hidroelektrik Santrallerin Çevresel ve Sosyal Etkileri Üzerine Bir Çalışma
}

\author{
Cengiz Koç ${ }^{1 *}$ \\ ${ }^{1}$ Muğla Sıtkı Koçman Üniversitesi, Mimarlık Fakültesi, Şehir ve Bölge Planlama Bölümü, Muğla, Türkiye (ORCID: 0000-0001-7310-073X) cengizko9@gmail.com
}

(İlk Geliş Tarihi 21 Nisan 2020 ve Kabul Tarihi 8 Ekim 2020)

(DOI: 10.31590 /ejosat.724940)

ATIF/REFERENCE: Koç, C. (2020). Mini-hidroelektrik Santrallerin Çevresel ve Sosyal Etkileri Üzerine Bir Çalışma. Avrupa Bilim ve Teknoloji Dergisi, (20), 35-41.

\section{$\ddot{O} z$}

Bu çalışma, Türkiye'nin Muğla ili, Ula ilçesi, Kavaklı köyü mevkiinde nehir tipi mini hidroelektrik santral olarak inşa edilen Namnam hidroelektrik santralin çevresel ve sosyal etkilerini incelenmek amacıyla yapılmıştır. Santralin çevresel ve sosyal etkilerini belirleyebilmek için yörede yaşayanlar, yetkililer ve teknik personel arasında tartışmalar ve arazi ziyaretleri yapılmıştır. Daha sonra, çevresel ve sosyal etkiler için düzenleme derecesi ve çevresel etki değeri puanları kullanılarak bilimsel olarak analiz edilmiştir. İncelenen Namnam hidroelektrik santrali için düzenleme derecesi 1. Sınıf, durumu ise "yüksek", çevresel etki değerinin puanı ise -15 olarak hesaplanmıştır. Bu durumda, Namnam hidroelektrik santralin bazı çevresel kaygıları tetiklediği, ancak topluma önemli derecede pozitif sosyal etki yaptığı ortaya konmuştur. Santral yeşil enerji üretimine bir katkı sunmaktadır. Bu nedenle, inşa edilmiş Namnam hidroelektrik santralin olumlu ve olumsuz yönleri değerlendirildiğinde ülkemiz için bir kazanç olduğu sonucuna ulaşılabilir. Ayrıca, yürütülen çalışmanın sonuçları dikkate alınarak olumsuz çevresel etkileri en aza indirecek veya ortadan kaldıracak önerilerde bulunulmuştur.

Anahtar Kelimeler: mini hidroelektrik santraller, düzenleme derecesi, çevresel etki değeri, sosyal etkiler, Namnam hidroelektrik santral

\section{A Study on Environmental and Social Impacts of Mini-hydro Power Plants}

\begin{abstract}
This study was conducted to examine the environmental and social impacts of Namnam hydroelectric power plant constructed as river-run-off type of mini-hydropower plants in Kavaklı village, Ula district, Mugla province of Turkey. In order to determine the environmental and social impacts of the power plant, discussions and field visits were made among the local residents, officials and technical personnel. Then, environmental and social impacts were analyzed scientifically using of regulation degree and environmental impact value scores. For the Namnam hydroelectric power plant, class and status of the regulation degree was 1 and "high". Environmental impact score was calculated as -15. In this case, it was demonstrated that the Namnam hydroelectric power plant has stimulated some environmental concerns, but has a significant positive social impact on the society. This power plant makes a contribution to green energy production. Therefore, when the positive and negative aspects of the constructed Namnam hydroelectric power plant are evaluated, it can be concluded that there is a gain for our country. In addition, suggestions were made considering the results of the study carried out.
\end{abstract}

Keywords: mini hydroelectric power plants, regulation degree, environmental impact value, social effects, Namnam hydroelectric power plant,

\footnotetext{
* Sorumlu Yazar: cengizko9@gmail.com
} 


\section{Giriş}

Hidroelektrik enerji, Türkiye'de dahil olmak üzere dünyadaki elektrik üretiminin önemli bir bölümünü oluşturmaktadır. Ülkemizde 2019 yılı verilerine göre kamu ve özel sektör tarafından inşa edilen 644 adet hidroelektrik santralin toplam kurulu gücü $28423 \mathrm{MW}$, ortalama y1llık enerji üretimi ise $99050 \mathrm{GWh} / \mathrm{y}$ 1l dır. Ülkemizde teknik ve ekonomik olarak geliştirilebilecek $180000 \mathrm{GWh} / \mathrm{y} 1 \mathrm{l}$ hidroelektrik enerji potansiyelinin $\% 55$ 'i geliştirilmiştir (DSİ, 2019). Ülkemizin mevcut hidroelektrik enerji potansiyeli Dünya hidroelektrik enerji potansiyelinin \%1,5'ini, Avrupa hidroelektrik enerji potansiyelinin ise \%17,6'sinı oluşturmaktadır (Koç, 2018). Norveç Su Kaynakları ve Enerji Müdürlüğü verilerine göre Norveç'in toplam hidroelektrik enerji potansiyeli $159 \mathrm{TWh} / \mathrm{y} 1 \mathrm{l}$ olup, bu potansiyelin yaklaşık $120 \mathrm{TWh} / \mathrm{y} 1 \mathrm{l}$ geliştirilmiştir (Kjaerland, 2007). Diğer yandan, Çin hızla büyüyen ekonomisini desteklemek için 2010 yılında hidroelektrik enerjiden 194 GW'lk üretim hedeflemiştir (Chang vd., 2010). Buna ek olarak, Hindistan hidroelektrik geliştirme konusunda dünyanın ilk beş ülkesi içerinde yer almaktadır (Kumar vd., 2010). Hidroelektrik enerji, ülkelerin ekonomisine ve toplumsal kalkınmasına önemli katkılar sağladığı için birçok ülkede oldukça popüler bir enerji kaynağıdır. Hidroelektrik enerji, Dünyada bugüne kadar elektriği geliştirmek için kullanılan en güvenli ve ucuz yenilenebilir enerji kaynaklarından biridir (Evans vd., 2009; Sims vd., 2003; Jager \& Smith, 2008; Yüksel, 2010). Bu nedenle, birçok ülke hidroelektrik potansiyelini geliştirmek için yeni yerler araştırarak hidroelektrik potansiyelini artırmaya çalışmaktadır (Bayazıt vd., 2017; Nastase vd., 2017). Hidroelektrik projeleri üretilen güce bağlı olarak birkaç grupta sınıflandırılmaktadır. Sınıflandırma için kesin bir standart veya net bir kural yoktur (Rojanamon vd., 2009). Williams \& Porter (2006) 'e göre, büyük hidroelektrik projeleri $100 \mathrm{MW}$ 'tan daha fazla enerji üretmektedir. 10-100 MW orta, 1-10 MW küçük, 100 kW-1 MW mini hidroelektrik santral olarak isimlendirilmektedir. Sınıflandırma daha küçük seviyelere uzanmakta olup, 5-100 kW arası mikro hidroelektrik projeleri, üretilen kapasitenin $5 \mathrm{~kW}$ 'dan az olması durumunda ise piko hidroelektrik projeleri olarak isimlendirilir (Williams \& Porter, 2006). Rojanamon vd (2009), küçük hidroelektrik projelerin 2,5-25 MW enerji üretimi arasında değiştiğini bildirmektedir. Ayrıca, Paish (2002) \& Demirmas (2005) küçük hidroelektrik santraller için en yaygın kurulu güç değerini $10 \mathrm{MW}$ olarak belirlemişlerdir. Ülkelerin çoğu mevcut durumda büyük ve orta ölçekli hidroelektrik projeleri geliştirmişler ve günümüzde küçük ölçekli hidroelektrik projelere yönelmişlerdir (Bracken vd., 2014; Wagner vd., 2015). İskoçya, 2020 yılına kadar yenilenebilir kaynaklardan \% 100 enerji kaynağı elde etmeyi amaçlayan ülkelerden birisidir. İskoçya $1.5 \mathrm{GW}$ hidroelektrik santrali kurmuş ve hala 500 MW'lık bir potansiyele sahiptir. Ancak, bu $500 \mathrm{MW}$ potansiyel büyük ölçüde küçük ve mini hidroelektrik projelerinden oluşmaktadır (Sample vd., 2015). Enerji otoriteleri, çevresel konuları içeren bazı nedenler ile mini ve mikro seviyeki hidroelektrik santralleri yoğun olarak araştırmaktadır (Eriyagama vd., 2016; Morimoto \& Munasinghe, 2005). Bununla birlikte, Çin ve Brezilya gibi bazı ülkeler enerji talepleri nedeniyle hala büyük hidroelektrik projeler için yer belirlemektedir. Küçük ve mini hidroelektrik santraller, büyük hidroelektrik santrallere göre bazı dezavantajlarının yanı sıra birçok avantaja sahiptir. Avantajların çoğu çevresel endişeler üzerinedir. Küçük ve mini hidroelektrik santraller genellikle nehir tipi santraller olarak inşa edilmektedir. Bu nedenle, suyu depolamak için bir rezervuar yoktur. $\mathrm{Bu}$ nedenle, büyük rezervuarların aksine, nehir tipi hidroelektrik santrallerin doğal ortam biyolojik çeşitliliğine verdiği zarar minimumdur (Anderson vd., 2014; Winemiller vd., 2016). Ayrıca, büyük hidroelektrik santrallere göre sera gazları emisyonu çok azdır (Yah vd., 2017). Ayrıca, büyük rezervuarların çoğu için sedimantasyon önemli bir konudur (Adam vd., 2014). Ancak, nehir tipi hidroelektrik santrallerin, genellikle sediment çökeltim havuzuna sahip olması bu endişeyi azaltmaktadır (Weerakoon \& Rathnayake, 2007). Burada listelenmemiş olmasına karşın küçük ve mini hidroelektrik projelerde bazı dezavantaj vardır (Abbasi \& Abbasi, 2011; Gracey \& Verones, 2016). Bu avantajlar ve dezavantajlar, bir hidroelektrik santral kurulmadan önce yerel olarak (ilgili inşaat yerinde) tartışılmaktadır. Ancak, özellikle gelişmekte olan ülkelerde inşaatı tamalanıp işletme aşamasına geçen santallere minimum seviyede özen gösterilmektedir. Ülkemizde ve diğer birçok ülkede de aynı senaryo uygulanmaktadır. Hiç kimse ürettikleri enerji dışında gelişmiş nehir tipi hidroelektrik santralleri bilimsel olarak izlememektedir. Hidroelektrik santrallerin inşaatı ve işletilmesi sürecinde karşılaşılan sosyo-çevresel konuların belirlenmesi son derece önemlidir. Çünkü bu konular gelecekte geliştirilecek projeler için öğrenilmesi gereken dersleri oluşturmaktadır. Bu nedenle, yürütülen bu çalışma, nehir tipi mini-hidroelektrik santrallerin çevresel ve sosyal etkilerini belirlemek amacıyla yapılmıştır. Ayrıca, çalışmanın sonuçları dikkate alınarak, bu konuda çalışanlar için önerilerde bulunulmuştur.

\section{Materyal ve Metod}

\subsection{Materyal}

\subsection{1. Çalışma Alanı}

Proje alanı, Türkiye'nin Muğla ili, Ula ilçesi, Kavaklı köyü mevkii, Namnam çayı havzasında yer almaktadır. Namnam çayı havzası, Köyceğiz gölü kuzey havzalarından biri olup, Ege ve Akdeniz bölgelerinin birleştiği yerde bulunmaktadır (Türedi, 2006). Şekil 1'de Namnam çayı havzasının lokasyon haritası verilmektedir (Utku \& Ekinci, 2015). Havzanın uzun yıllar ortalama yağış miktarı 1045,9 mm dir (DMİ, 2018) ve yağışların çoğu k1ş mevsiminde meydana gelmektedir. Yağışların 580,24 mm kışın, 194,83 $\mathrm{mm}$ ilkbahar, 19,09 $\mathrm{mm}$ yaz ve $251,69 \mathrm{~mm}$ sonbaharda düşmektedir. Namnam çayı, Çiçek baba dağından doğan ve Köyceğiz gölüne dökülen bir bir akarsudur. Namnam Çayı, su toplama havzası içindeki birçok küçük akarsu kolunun birleşmesinden meydana gelmiştir. Namnam Çayının su toplama havzası $544 \mathrm{~km}^{2}$, uzunluğu $30 \mathrm{~km}$ dir. Çayın minimum, maksimum ve ortalama debisi, sirasiyla 0,960, 556 ve $7,698 \mathrm{~m}^{3} / \mathrm{s}$ dir. Çayın çevresindeki yoğun tarımsal faaliyetler su kalitesine olumsuz etki yapmaktadır. Yazın mevsimsel etkiler ile azalan sular yoğun olarak sulamada kullanılmaktadır. 


\subsubsection{Hidroelektrik Santral}

İnşa edilen Hidroelektrik Enerji Santrali (HES) Namnam çayı üzerinde yer almaktadır. HES için gerekli su Namnam çayından regülatör ile saptırılmaktadır. Hidroelektrik santral, Namnam çayının 195,5 m ile 395,0 m kotları arasında brüt $100,5 \mathrm{~m}$ düşüye sahiptir. Toplam türbin debisi $4,50 \mathrm{~m} 3 / \mathrm{s}$ olup, kurulu güç 3,72 MW dır. Yıllık enerji üretimi 1,76 $\mathrm{GWh}$ güvenilir olmak üzere toplam 13,72 GWh enerji üretebilmektedir. Yatırım maliyeti 5.121.397 US\$ dır. Namnam HES 2016 yılında enerji üretimine başlamıştır. Santral iki elektrik jeneratörüne bağlı iki yatay Franchis hidro türbinden oluşmaktadır. Namnam HES, regülatör, iletim kanalı, yükleme havuzu, cebri boru ve santral binasindan oluşmaktadır. Yüksek kotdan geçen iletim kanalı trapez kesitli açık kanal şeklinde inşa edilmiştir. Şekil 2, 3, 4 ve 5'de Namnam HES'e ait regülatör, balık geçidi, santral binası ve cebri boru güzergahına ilişkin bazı resimler verilmektedir.

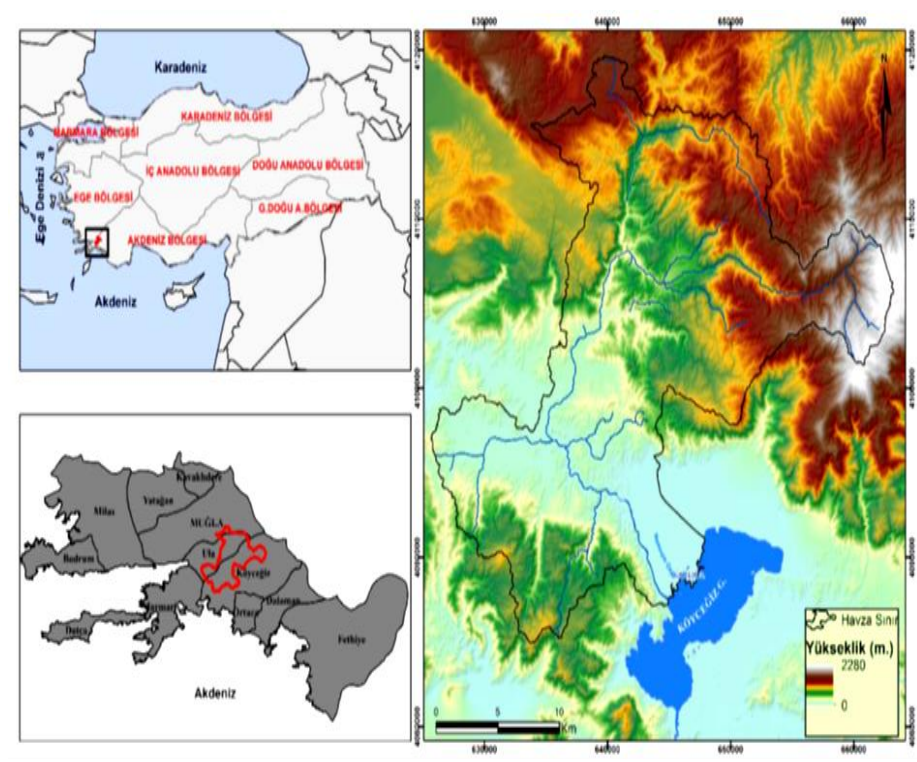

Şekil 1: Namnam Çayı Havzasının Lokasyon Haritası

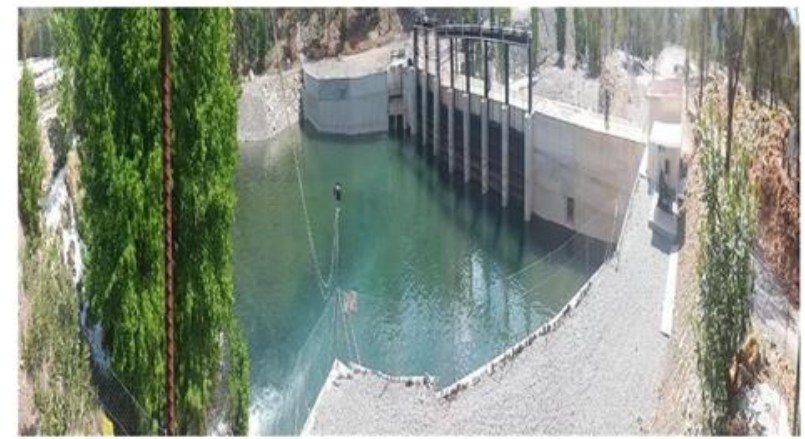

Şekil 2. Namnam HES regülatör

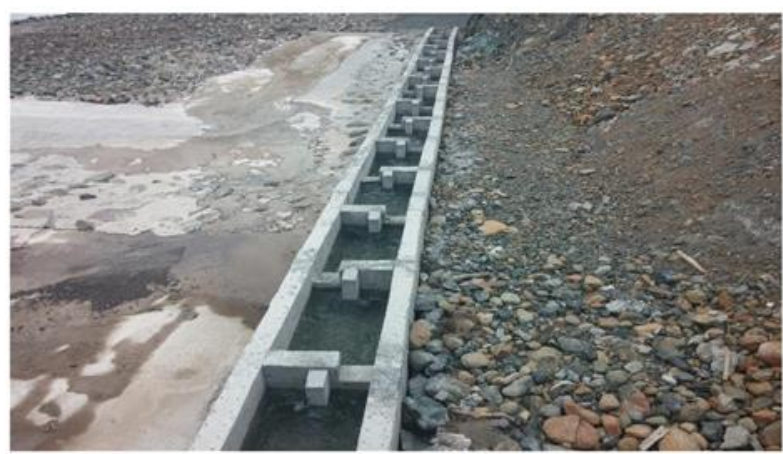

Şekil 3. Namnam HES regülatör balık geçidi

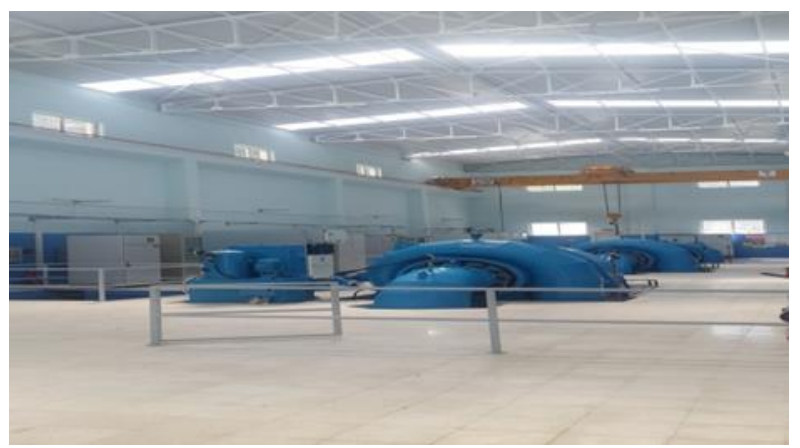

Şekil 4. Namnam HES türbinleri

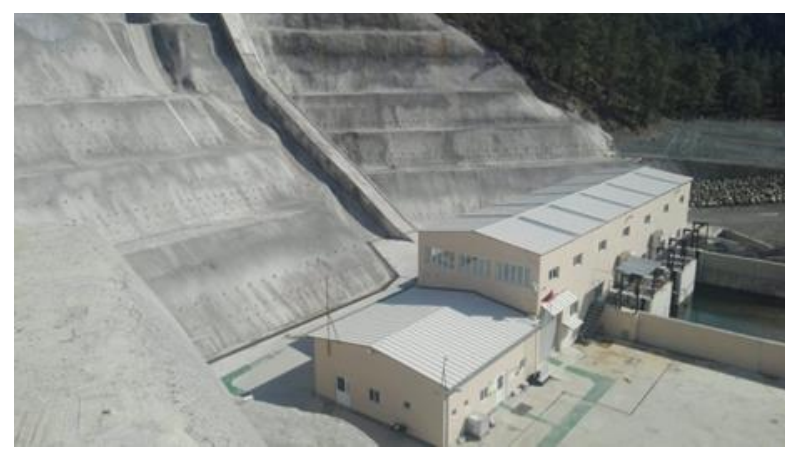

Şekil 5. Namnam HES binası ve cebri boru

\subsection{Metod}

\subsubsection{Düzenleme Derecesi (RD) ve Çevresel Etki Değeri (EIV)}

Mini hidroelektrik santralden kaynaklanan çevresel zararı ölçmek için çeşitli yöntemler kullanılmaktadır. Düzenleme derecesi ve çevresel etki değeri oluşabilecek zararı göstermenin iki farklı yöntemidir. Düzenleme derecesi, çevreye fiziksel olarak etki eden hidrolojik rejim özelliklerindeki değişimin neden olduğu etkiyi hesaplamanın bir ölçüsüdür (Steinmetz \& Sundqvist, 2014). Birçok araştırmacı bu parametreyi, yeni geliştirilen akış yapıları ve iklim değişikliğinden kaynaklanan çevresel zararları ölçmek için kullanmıştır (Arheimer vd., 2017; Zhangzhong vd., 2015). Düzenleme derecesi 1 nolu eşitlikte verilmektedir.

$\mathrm{RD}=\left(\mathrm{V}_{\text {store }} / \mathrm{V}_{\text {flow }}\right) \times 100 \%$

Eşitlikte, $\mathrm{RD}, \mathrm{V}_{\text {stored }}$ ve $\mathrm{V}_{\text {flow }}$ sirasıyla, regülasyon derecesi, depolanabilecek toplam su hacmi ve yıllık akış hacmidir. Hesaplanan RD değeri temel alınarak, akarsu üzerine akım 
düzenlemesinin etkisi sınıflandırılabilir. Tablo 1 düzenleme derecesine göre sınıflandırmayı vermektedir.

Tablo 1. Düzenleme derecesine göre çevresel etkinin siniflandirılması

(Steinmetz \& Sundqvist, 2014).

\begin{tabular}{lcc}
\hline Durum & Sinıf & Düzenleme derecesi \\
\hline Yüksek & 1 & $0,0.00$ \\
İyi & 2 & $0,9.99$ \\
Orta & 3 & $1,019.99$ \\
Yetersiz & 4 & $2,049.99$ \\
Zayıf & 5 & 50,100 \\
\hline
\end{tabular}

Çevreye verilen toplam etki Çevre Etki Değeri (EIV) kullanılarak hesaplanabilir. Etki değerlerinin aritmetik toplamı, santralin ülke için bir tehdit veya avantaj olup olmadığı hakkında genel bir fikir vermektedir. İndeks sadece hidroelektrik santraller için değil, aynı zamanda çevre ile ilgili diğer birçok faaliyet için de kullanılmıştır (Coelho \& Brito, 2012; Safont vd., 2012). Literatürde indeksi ifade etmenin çeşitli yolları olmasına karşın 2 nolu eşitlikte verilen matematiksel açıklama kullanılmıştır.

$$
\mathrm{EIV}=\sum_{\mathrm{i}=1}^{\mathrm{n}}\left(\mathrm{V}_{\mathrm{i}} \mathrm{xW} \mathrm{W}_{\mathrm{i}}\right)
$$

Eşitlikte, $\mathrm{V}_{\mathrm{i}}$, çevresel kalite parametresinin göreli değişimi, $\mathrm{W}_{\mathrm{i}}$, parametrelerin göreceli önemi veya ağırlığıdır ve $n$, parametrelerin toplam sayısıdır.

\subsubsection{Arazi Gezileri}

Nisan 2019'den Ekim 2019'a kadar geçen süreçte incelenen mini hidroelektrik santralin inşa edildiği alana ve çevresine çeşitli arazi ziyaretleri düzenlenmiştir. Santral, regülatör, su giriş yapısı, iletim kanalı, yükleme havuzu ve santralin çevresinde yer alan köyler ziyaret edilmiştir. Santral ve su alma, iletme, yükleme yapılarının teknik detayları santralde çalışan teknik yetkililerden alınmıştır. Ayrıca, enerji üretiminin tasarımı ve ekonomisi de dahil olmak üzere tüm teknik özelliklere ilişkin bilgiler elde edilmiştir. Arazi gezilerinden elde edilen gözlemler, Namnam mini hidroelektrik santralinin EIV değerini hesaplamak için kullanılmıştır. Ayrıca, bölgede yer alan flora ve faunayı belirlemeye çalışılmıştır. Arazide çalışanlar flora ve fauna listesinin tümünü tanımlamak için gerekli özel bilgi ve deneyime sahip değildir, ancak, arazi gezileri sırasında bunlardan bazılarına tanıklık etmişlerdir. Mini hidroelektrik santralin mevcut flora ve fauna üzerindeki potansiyel tehditlerini tanımlamak için biyolojik çeşitlilik analizinin yapılması önerilmektedir. Ayrıca, günlük yaşam üzerine mini hidroelektrik santralin artıları ve eksileri köy halkı ile tartışılmıştır. Ayrıca, Bir anket çalışması uygulanarak çevre köylerin bazı önemli duyarlılıkları belirlenmiştir.

\section{Sonuçlar ve Tartışma}

Çalışma alanına ilişkin hidrolojik rejim analizi Bergkamp vd (2000) tarafindan verilen varyasyon özellikleri referansı kullanılarak yürütülmüştür. $\mathrm{Bu}$ bağlamda, çalışmadan elde edilen sonuçlar aşağıda verilmektedir.
Namnam mini-hidroelektrik santralinin ortalama debisi 4,50 $\mathrm{m}^{3} / \mathrm{s}$ olup, sabit bir değer göstermektedir. Namnam çayı su akışının planlamada belirtilen miktarı üst kottan geçen iletim kanalıyla mini-hidroelektrik santrale iletilmektedir. $\mathrm{Bu}$ nedenle, suyun santrale iletiminden kaynaklanan bir değişim söz konusu değildir. Proje alanında, özellikle kış mevsiminde normal ve yoğun yağışlar görülmektedir. Ancak, yaz döneminde mevcut suyun bir kısmı sulama hizmetlerinde kullanıldığı için enerji üretimi azalmakta yâda hiç yapılamamaktadır. Namnam çayı kısa süreli düşük akışlar kadar kısa süreli taşkın piklerine de sahiptir. Nehir taşkınları uzadığı için nehirdeki hızlı değişimler daha kısa sürede görülebilmektedir. Akışın büyüklüğü, akışın süresi, akışın sıklığı, taşkın zamanlaması ve değişim hızı bir nehirdeki fiziksel ve biyolojik süreçleri etkileyen temel özellikler olarak tanımlanmaktadır (Renafalt vd., 2010). Bu temel özelliklere ve Namnam çayı için yukarıda belirtilen bulgulara dayanarak, Tablo 2, Namnam çayının akış rejimi özellikleri için sunulmaktadır. Tablo 2'ye göre iklim koşullarından kaynaklanan hidrolojik rejim özellikleri açıçca görülmektedir. $\mathrm{Bu}$ nedenle, havzaya yağışın gelecekteki eğilimlerini belirlemek ve daha sonra gelecekteki akış koşullarını tahmin etmek için bir iklimsel analiz önerilmektedir.

İncelenen Namnam mini-hidroelektrik santral için düzenleme derecesi hesaplanmıştır. Mini-hidroelektrik istasyonunda rezervuar yoktur. Regülatör, suyu üst kotlarda inşa edilen iletim kanalına saptırmak için kullanılmaktadır. Ancak, akarsuyun membasındaki su seviyesi regülatör ile kabartılmaktadır. $\mathrm{Bu}$ nedenle, zorunlu olarak regülatörün membasında küçük bir rezervuar oluşmaktadır. Namnam çayının ortalama akışı 7,69 m³ $/ \mathrm{s}$, mini-hidroelektrik santralin ortalama akışı ise $4,50 \mathrm{~m}^{3} / \mathrm{s}^{\prime}$ dir. $\mathrm{Bu}$ nedenle, $\mathrm{V}_{\text {stored }}$ (yıllık depolanabilecek su hacmi) 242,7 milyon $\mathrm{m}^{3}$, $\mathrm{V}_{\text {flow }}$ (yıllık akış hacmi) 142 milyon $\mathrm{m}^{3}$ 'dür. $\mathrm{V}_{\text {flow }}$ değeri ile hesaplanırken regülatör gövdesinden savaklanan su miktarı göz ard1 edilmektedir. Mini-hidroelektrik santralin RD değeri 0,017 olarak hesaplanmıştır. $\mathrm{Bu}$ durumda, santral için düzenleme derecesi 1. sınıf, durum ise "yüksek" olarak belirlenmiştir. Bu nedenle, Namnam mini-hidroelektrik santrali hidrolojik rejim duyarlılığı yönünden çevreye potansiyel olumsuz etki yaratmamaktadır. Mini-hidroelektrik santral için regülatör girişinin uzaması mevcut akarsu yatağındaki sediment akışını üst kotlardan geçen kanal ile önemli ölçüde tutmaktadır.

\begin{tabular}{|c|c|c|}
\hline $\begin{array}{l}\text { Akış } \\
\text { Özellikleri }\end{array}$ & Seçenekler & Ekosistem Yanıtı \\
\hline $\begin{array}{l}\text { Akış } \\
\text { Büyüklüğü }\end{array}$ & Sabit Akış & $\begin{array}{l}\text { Kıyı türlerinin } \\
\text { oluşmamasına ve ekzotik } \\
\text { türlerin istilasına katkıda } \\
\text { bulunabilir. Zayıf } \\
\text { rakiplerin kaybı ve } \\
\text { rekabetçi türlerin baskınlığı } \\
\text { artar }\end{array}$ \\
\hline $\begin{array}{l}\text { Ak1ş } \\
\text { sürekliliği }\end{array}$ & Değişiklik yok & $\begin{array}{l}\text { Toprak erozyonu veya } \\
\text { biyolojik çeşitlilik } \\
\text { tehditleri gibi çevreyi saran } \\
\text { potansiyel zarar yoktur }\end{array}$ \\
\hline $\begin{array}{l}\text { Taşkın } \\
\text { zamanı }\end{array}$ & $\begin{array}{l}\text { Mevsimsel akış } \\
\text { değişkenlerinin } \\
\text { değişimi/kaybı }\end{array}$ & $\begin{array}{l}\text { Gelişme hızının azalmasına } \\
\text { ve biribirini takip eden } \\
\text { türlerin değişimine neden } \\
\text { olan rahatsız edici yaşam } \\
\text { döngüleri. Ayrıca, }\end{array}$ \\
\hline
\end{tabular}

Tablo 2. Hidrolojik rejim özelliklerinin sonucu 


\begin{tabular}{|c|c|c|}
\hline & & $\begin{array}{l}\text { azaltılmış bir yaşam alanı } \\
\text { olacaktır }\end{array}$ \\
\hline \multirow[b]{2}{*}{ Akış süresi } & $\begin{array}{l}\text { Kısa süreli düşük } \\
\text { akışlar }\end{array}$ & $\begin{array}{l}\text { Sucul habitatların } \\
\text { mevcudiyetini artırma }\end{array}$ \\
\hline & $\begin{array}{l}\text { Kısa süreli taşkın } \\
\text { pikleri }\end{array}$ & $\begin{array}{l}\text { Nehir yatağındaki kara } \\
\text { organizmalarının zarar } \\
\text { görmesi }\end{array}$ \\
\hline $\begin{array}{l}\text { Akış } \\
\text { değişim } \\
\text { hızı }\end{array}$ & $\begin{array}{l}\text { Nehir } \\
\text { seviyesindeki } \\
\text { hızlı değişimler }\end{array}$ & $\begin{array}{l}\text { Kıyı bölgesi ve bitki } \\
\text { örtüsünün kaybı. } \\
\text { Organizmalarının } \\
\text { yıkanması ve karaya } \\
\text { tutunması nedeniyle kıyı } \\
\text { organizmalarının } \\
\text { oluşturulamaması. }\end{array}$ \\
\hline
\end{tabular}

$\mathrm{Bu}$ uzaklıkta akış çok düşüktür, bu nedenle, sediment akışı ihmal edilebilir düzeydedir. Bu durum, sucul yaşam ve çevresi üzerine olumsuz çevresel etki yapar. Bununla birlikte, üst kotlardan geçen kanalın eleklerinde tutulan sediment tekrar nehir mansabına bırakılır. Bu sediment, membadan mansaba doğru besin maddeleri akışının geri kazanılmasına yardımcı olur.

$\mathrm{Bu}$ çalışmada su kalitesi analizleri yapılmamıştır. Minihidroelektrik santrallerin su kalitesini değiştirmeye yönelik bir etkiye sahip olmadığı düşünülmektedir (Koç, 2018). Bu varsayım, bir rezervuara sahip olmayan Namnam minihidroelektrik santrali için de geçerlidir. Bir rezervuar ile birleşik olsaydı su kalitesi hidrolik tutulma süreci nedeniyle etkilenebilirdi. Ancak, roto-dinamik makinelerin çalışması nedeniyle bazı yağ ve gres kirlilikleri olabilmektedir. Bu nedenle, türbinlerden su salınımı için kullanılan yăg ve gres için su kalitesi analizi yapılması tavsiye edilmektedir.

Namnam mini-hidroelektrik santrali için çevresel etki değeri (EIV) hesaplanmıştır. Daha önce de belirtildiği gibi EIV, çevreye neden olabilecek potansiyel etkiyi belirtmek için kullanılan yöntemlerden birisidir. Tablo 3, üç alt bölümde (fiziksel, biyolojik ve sosyal ortamlar) kullanılan farklı ağırlık değerlerini vermektedir. Ayrıca, EIV için hesaplamaları da göstermektedir. EIV hesaplarının yapılmasında arazi gözlemleri ve çevre köylerde yaşayanlar ile yapılan inceleme ve tartışmalar yardımcı olmuştur. Olumlu ve olumsuz etkilerin aritmetik toplamına göre Namnam mini-hidroelektrik santrali EIV değeri -15 olarak hesaplanmıştır. Bu nedenle, olumlu ve olumsuz etkilerin ağırlıkları karşılaştırıldığında minihidroelektrik santrallerin çevre için potansiyel bir tehdit olduğu sonucuna ulaşılabilir. EIV sonuçları, alt bölümler üzerindeki etkinin daha iyi anlaşılması için Şekil 6'da sunulmuştur.

Şekil 6, mini-hidroelektrik santralinin fiziksel ve biyolojik çevre üzerindeki olumsuz etkilerini açıkça göstermektedir. Biyolojik çevre üzerindeki olumsuz etki oldukça önemlidir. $\mathrm{Bu}$ nedenle, ayrıntılı bir biyolojik çeşitlilik analizi yapılmalıdır. Bununla birlikte, mini-hidroelektrik santral, fiziksel çevre ve sosyal çevre üzerinde olumlu bir etki yapmıştır. Komposit üretmek için atıkların yeniden geri dönüştürülmesi ve ağaçlandırma çalışmaları hidroelektrik santralinin önemli olumlu etkilerindendir. Sosyal çevrenin olumlu etkileri köy halkı arasındaki tartışmalardan elde edilmiştir. Köye ait bazı yolların yapılması, beton veya asfalt kaplanması, santralin yöre halkı için iş olanakları yaratması, yörede camilerin ve topluluk salonlarının yenilenmesi Namnam mini-hidroelektrik sanralin olumlu sosyal etkilerinden birkaçını oluşturmaktadır.

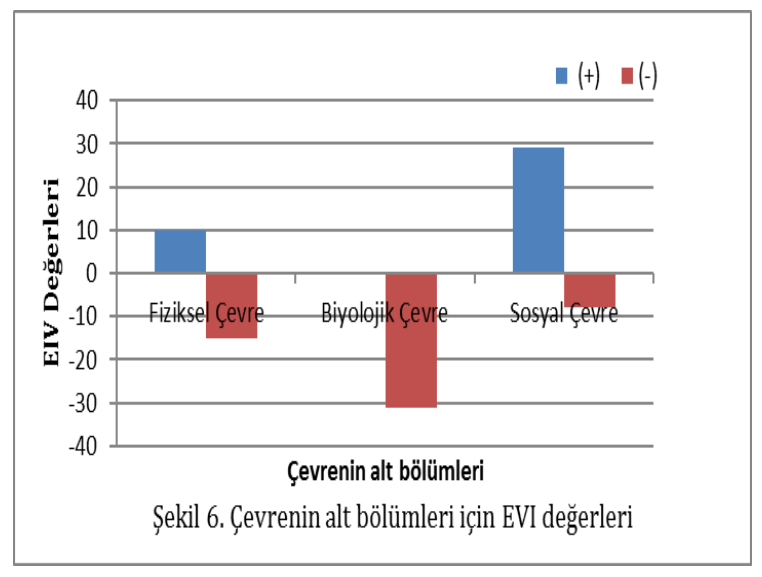

Tablo 3. EIV hesaplamalart

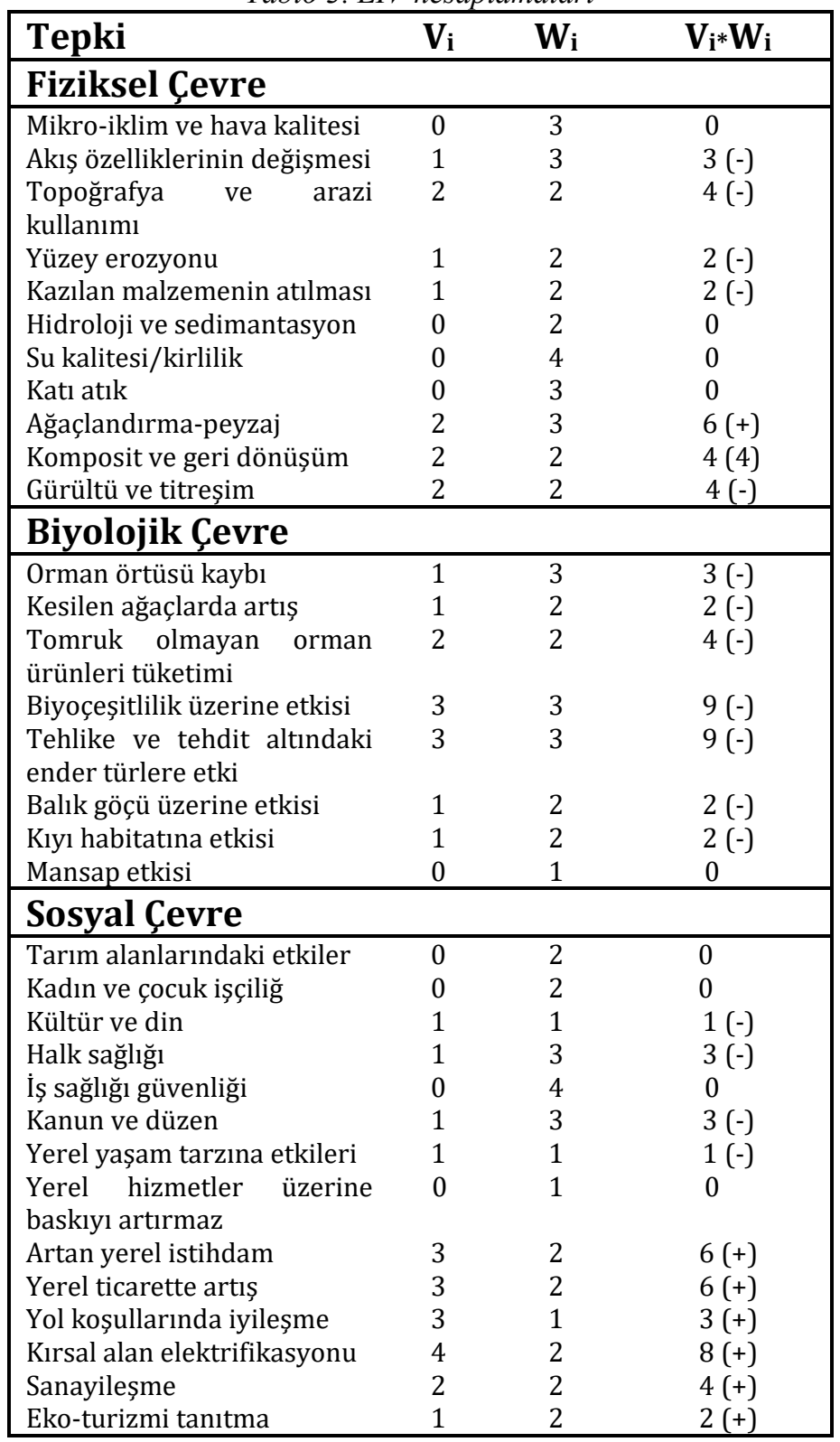

(-) negatif etki, (+) pozitif etki

\section{Sonuç ve Öneriler}

$\mathrm{Bu}$ çalışma, ülkemizde verimli şekilde işletilen bir minihidroelektrik santral olan Namnam santralinin potansiyel sosyal ve çevresel etkilerini saptamak amaciyla yürütülmüştür. 
Santralin çevre üzerindeki olumsuz etkileri bazı endişelerin ortaya çıkmasına neden olmaktadır. Namnam minihidroelektrik santrali ülke için bir kazanımdır. Bununla birlikte, olumsuz etkileri çok daha düşük bir seviyeye getirmek için düzeltme ve giderme yöntemlerini belirlemek için gelecekte daha çok araştırma yapılması önerilmektedir. $\mathrm{Bu}$ çalışmaya su kalitesi analizi ve biyolojik çeşitlilik analizi de dahil edilmelidir. Ayrıca, ülkedeki diğer mini hidroelektrik santralleri değerlendirmek için EIV ve RD değerlerinin kullanılması önerilir. Değerlendirmeye dayanarak, yetkililer, önemli negatif EIV puanları bulurlarsa, mini-hidroelektrik santrallerin sürekliliği ve çevre üzerine etkileri yeniden düşünülmelidir. Bununla birlikte, değerlendirilen minihidroelektrik santralinin EIV'de pozitif puanları veya önemsiz negatif değerleri varsa, bunlar da ödüllendirilmelidir. EIV değerleri hidroelektrik santrallerin hem inşaat hem de işletme süreçleri için belirlenmelidir. Ayrıca, inşaat döneminde ekosisteme kalıcı zararların verilmemesi, söz konusu yapıların ve zorunlu açılan yolların peyzaj bütünlüğüne zarar vermemesi için gerekli özen gösterilmelidir.

\section{Kaynakça}

Abbasi, T., \& Abbasi, S. (2011). Small Hydro and the Environmental Implications of Its Extensive Utilization. Renewable and Sustainable Energy Reviews 15 (4): 213443.

Adam, N., Erpicum, S., Archambeau, P., Pirotton, M., \& Dewals, B. (2014). Stochastic Modelling of Reservoir Sedimentation in a Semi-arid Watershed. Water Resources Management 29 (3): 785-800.

Anderson, D., Moggridge, H., Warren, P., \& Shucksmith, J. (2014). The Impacts of 'Run-of-River' Hydropower on the Physical and Ecological Condition of Rivers. Water and Environment Journal 29 (2): 268-76.

Bayazıt, Y., Bakış, R., \& Koç, C. (2017). An Investigation of Small Scale Hydropower Plants Using the Geographic Information System. Renewable and Sustainable Energy Reviews 67: 289-94.

Bergkamp, G., McCartney, M., Dugan, P., McNeely, J., \& Acreman, M. (2000). Dams, Ecosystem Functions and Environmental Restoration: Thematic Review II. 1 World Commission on Dams, Cape Town, South Africa

Bracken, L., Bulkeley, H., \& Maynard, C. (2014). Microhydro Power in the UK: The Role of Communities in an Emerging Energy Resource. Energy Policy 68: 92-101.

Chang, X., Liu, X., \& Zhou, W. (2010). Hydropower in China at Present and Its Further Development. Energy 35 (11): 4400-6.

Coelho, A., \& De Brito, J. (2012). Influence of Construction and Demolition Waste Management on the Environmental Impact of Buildings. Waste Management 32 (3): 532-41.

Demirbas, A. (2005). Potential Applications of Renewable Energy Sources, Biomass Combustion Problems in Boiler Power Systems and Combustion Related Environmental Issues. Progress in Energy and Combustion Science 31 (2): 171-92.

DMİ (Devlet Meteoroloji İşleri). (2018). Köyceğiz Meteoroloji İstasyonu Rasat Verileri 1975-2018, Ankara

DSİ, (2019). Ülkemizde İşletmeye Açılan Hidroelektrik Santraller. Tarım ve Orman Bakanlığı, Devlet Su İşleri Genel Müdürlüğü, İşletme ve Bakım Daire Başkanlığı, İşletmeye Açılan HES'ler Raporu, 15s, Ankara
Eriyagama, N., Smakhtin, V., \& Jinapala, K. (2016). The Sri Lanka Environmental Flow Calculator: A Science-Based Tool to Support Sustainable National Water Management. Water Policy 18 (2): 480-92.

Evans, A., Strezov, V., \& Evans, T. (2009). Assessment of Sustainability Indicators for Renewable Energy Technologies. Renewable and Sustainable Energy Reviews 13 (5): 1082-8.

Gracey, E., \& Verones, F. (2016). Impacts from hydropower production on biodiversity in an LCA framework-review and recommendations. The International Journal of Life Cycle Assessment 21(3): 412-28.

Jager, H., \& Smith, B. (2008). Sustainable Reservoir Operation: Can We Generate Hydropower and Preserve Ecosystem Values ?. River Research and Applications 24, 340-352

Kjærland, F. (2007). A Real Option Analysis of Investments in Hydropower-The Case of Norway. Energy Policy 35 (11): 5901-8.

Koç, C. (2018). A Study on Operation Problems of Hydropower Plants Integrated with Irrigation Schemes Operated in Turkey. International Journal of Green Energy, Volume 15, Issue 2, 129-135,

Kumar, A., Kumar, K., Kaushik, N., Sharma, S., \& Mishra, S. (2010). Renewable Energy in India: Current Status and Future Potentials. Renewable and Sustainable Energy Reviews 14 (8): 2434-42.

Morimoto, R., \& Munasinghe, M. (2005). Small Hydropower Projects and Sustainable Energy Development in Sri Lanka. International Journal of Global Energy, Issues 24 $(1 / 2): 3$.

Nastase, G., Şerban, A., Năstase, A., \& Iordan, N. (2017). Hydropower Development in Romania. A Review from Its Beginnings to the Present. Renewable and Sustainable Energy Reviews 80: 297-312.

Paish, O. (2002). Small Hydro Power: Technology and Current Status. Renewable and Sustainable Energy Reviews 6 (6): 537-56.

Renafalt, B., Jansson, R., \& Nilsson, C. (2010). Effects of Hydropower Generation and Opportunities for Environmental Flow Management in Swedish Riverine Ecosystems. Freshwater Biology 55 (1): 49-67.

Rojanamon, P., Chaisomphob, T., \& Bureekul, T. (2009). Application of Geographical Information System to Site Selection of Small Run-of-River Hydropower Project by Considering Engineering/Economic/Environmental Criteria and Social Impact. Renewable and Sustainable Energy Reviews 13 (9): 2336-48.

Safont, E., Vegas-Vilarrúbia, T., \& Rull, V. (2012). Use of Environmental Impact Assessment (EIA) Tools to Set Priorities and Optimize Strategies in Biodiversity Conservation. Biological Conservation 149 (1): 113-21.

Sample, J., Duncan, N., Ferguson, M., \& Cooksley, S. (2015). Scotland's Hydropower: Current Capacity, Future Potential and the Possible Impacts of Climate Change. Renewable and Sustainable Energy Reviews 52: 111-22.

Sims, R., Rogner, H., \& Gregory, K. (2003). Carbon Emission and Mitigation Cost Comparisons between Fossil Fuel, Nuclear and Renewable Energy Resources for Electricity Generation. Energy Policy 31 (13): 1315-26.

Steinmetz, M., \& Sundqvist, N. (2014). Environmental Impacts of Small Hydropower Plants-A Case Study of 
Borås Energi och Miljö’s Hydropower Plants. Master of Science thesis, Chalmers University of Technology.

Türedi. M., (2006). Köyceğiz Gölü (Limnolojik Etüd) Yayınlanmamış Yüksek Lisans Tezi, Marmara Üniversitesi Eğitim Bilimleri Enstitüsü Ortaöğretim Sosyal Alanlar Eğitim Anabilim Dalı Coğrafya Öğretmenliği Bilim Dalı, İstanbul.

Utlu, M., \& Ekinci, D. (2015). Namnam Çayı Havzasının (Muğla) Uygulamalı Hidrografyası. İstanbul Üniversitesi, Edebiyat Fakültesi, Coğrafya Bölümü, Coğrafya Dergisi, Say1 30 Sayfa 38-60.

Wagner, B., Hauer, C., Schoder, A., \& Habersack, H. (2015). A Review of Hydropower in Austria: Past, Present and Future Development. Renewable and Sustainable Energy Reviews 50: 304-14.

Weerakoon, S. B., \& Rathnayake, U. S. (2007). Effect of the Entrance Zone on the Trapping Efficiency of Desilting Tanks in Run-of-River Hydropower Plants. In International Conference on Small Hydropower-Hydro Sri Lanka, 22-4.

Williams, A., \& Porter, S. (2006). Comparison of Hydropower Options for Developing Countries with Regard to the Environmental, Social and Economic Aspects. In Proceedings of the International Conference on Renewable Energy for Developing Countries, 1-17.

Winemiller, K., McIntyre, P., Castello, L., Fluet-Chouinard, E., Giarrizzo, T., Nam, S., Baird, I., Darwall, W., Lujan, N., Harrison, I., Stiassny, M., Silvano, R., Fitzgerald, D., Pelicice, F., Agostinho, A., Gomes, L., Albert, J., Baran, E., Petrere, M., Zarfl, C., Mulligan, M., Sullivan, J., Arantes, C., Sousa, L., Koning, A., Hoeinghaus, D., Sabaj, M., Lundberg, J., Armbruster, J., Thieme, M., Petry, P., Zuanon, J., Vilara, G., Snoeks, J., Ou, C., Rainboth, W., Pavanelli, C., Akama, A., Soesbergen, A., \& Saenz, L. (2016). Balancing Hydropower and Biodiversity in the Amazon, Congo, and Mekong. Science 351 (62-69): 1289.

Yah, N., Oumer, A., \& Idris, M. (2017). Small Scale HydroPower as a Source of Renewable Energy in Malaysia: A Review. Renewable and Sustainable Energy Reviews 72: 228-39.

Yüksel, I. (2010). Hydropower for Sustainable Water and Energy Development. Renewable and Sustainable Energy Reviews 14 (1): 462-9.

Zhangzhong, L., Yang, P., Ren, S., Liu, Y., \& Li, Y. (2015). Flow Characteristics and Pressure-Compensating Mechanism of Non-pressure-Compensating Drip Irrigation Emitters. Irrigation and Drainage 64 (5): 63746. 